\title{
Consensus statements
}

The following statements represent the consensus of views of the symposium participants, having been agreed in the final session commencing at $2.00 \mathrm{pm}$ on 25 June 1999. The consensus discussion took place after three workshop discussions, during which the main issues emerging from the papers read at the symposium were considered. Participants were given the opportunity to revise the statements and changes were made accordingly by the Editors. Participants were given the opportunity to either associate or disassociate themselves from the following statements.

Low-digestible carbohydrates (LDCs) are important regulators of gastrointestinal function and bowel habit. They also cause increases in abdominal gas and have laxative effects, which may be gentle or severe. Severity varies between individual consumers and between different LDCs. Each individual may experiment with intake amounts and make adjustments based on their own experience - as they may do routinely with everyday foods having the same effects when eaten to excess.

(1) There are currently no known safety issues concerning approved LDCs under conditions of intended use.

(2) There is a considerable body of scientific evidence for the existence of beneficial effects associated with the consumption of appropriate levels of LDCs in relation to reduced caloric value, hypocarioenicity, prebiotic effects, reduced glycaemia and improved gastrointestinal function and health.
(3) LDCs occur naturally in the diet and gastrointestinal responses experienced after consumption of LDCs added to the diet are of the same nature (although of varying severity) as those experienced by individuals eating a normal mixed diet.

(4) Gastrointestinal side-effects following excessive consumption of LDCs are considered a physiological overload phenomenon that can be mitigated by reducing one's intake.

(5) Because of wide variations in individual gastrointestinal responses, threshold levels for the consumption of LDCs obtained under experimental conditions have limited value for the public.

(6) There is a clear and incontrovertible need for education of health professionals and the public about the potential beneficial effects of LDC consumption and about the tolerance aspects.

(7) Current EU legislation restricts the use of some LDCs in certain applications. There is no consumer benetit in restricting the application of polyols to energy-reduced and no-added-sugar products

(8) Current food labelling regulations do not allow promotion of the potential physiological benefits and possible disease-preventitive effects of LDCs. As a result the consumer is uninformed about current and new food products.

(9) There is no scientific basis for a regulatory distinction between LDCs in their classification as food ingredients versus food additives.

Symposium participants associating with the statements

(three unnamed participants asked to be anonymous and not associated)

Albert Bär, Bioresco, Switzerland.

Sue Barlow, Brighton, UK.

Hans Bertlesen, MD Food Ingredients, Denmark.

Mike Booth, Roquette UK, Tunbridge Wells.

Francis Bornét, Eridania Beghin Say, Belgium.

Louise Botham, British Sugar, UK.

Saskia Brokx, Purac Biochem BV, The Netherlands.

Alan Curruthers, Adams (Warner Lambert), UK.

Clare Chapman, United Biscuits Ltd, UK.

Steve Clarke, ABR Foods, UK.

Jim Currie, Scanchem, Ltd, UK.

John H. Cummings, Ninewells Hospital, Dundee, UK.

Nick Dunning, Cultor Ltd, UK.

Michelle Finney, Salford University, UK.

Colin Gutteridge, Cadbury Schweppes plc, UK.

John Howlett, Middlesex, UK.

David Howling, Kelloggs, UK.

Leen Van Den Heuvel, Lonza Benelux BV, The Netherlands.

George Koutsou, Salford University, UK.

Lionel Lafay, INSERM, France.

Phillip Lawson, Cerestar UK, Ltd.
Adam Lee, Salford University, UK.

Geoffrey Livesey, Independent Nutrition Logic, UK.

Phillippe Marieau, EU, Hospital Georges Pompidou, France. Olive Murphy, Leatherhead Food RA, UK.

Tom O'Conner, McNeil Speciality Products, Eire.

Tammy Pepper, Cultor Ltd, UK.

Patricia Richmond, A.E. Staley, U.S.A.

Joanne Smullen, Salford University, UK

Birgit Schindler, Hohenheim University, Germany.

Anke Sentko, Palatinit GmbH, Germany.

Karen Simpkin, Simpkin \& Co Ltd, UK.

Don Stewart, London, UK.

David Storey, Salford University, UK.

Jean Luc-Volatier, CREDOC, France.

Marteen Van Nuenen, TNO Nutrition \& Food Research,

The Netherlands.

Dennis Walker, Lofthouse of Fleetwood Ltd, UK.

Ian White, Cerestar Ltd, UK.

Daniel Wills, Roquette Freres, France.

Wolfgang Scheppach, University of Wuerzburg, Germany. Albert Zumbé, Salford University, UK. 